\title{
Role of Covering lleostomy in Causation of Anastomotic Strictures in Low Anterior Resections for Rectum Carcinoma
}

\section{O papel da ileostomia de proteção como causa das estenoses anastomóticas nas ressecções anteriores de reto}

\author{
Mudassir Ahmad Khan ${ }^{10}$ Rauf A. Wani ${ }^{2}$ Asif Mehraj ${ }^{2}$ Arshad Baba ${ }^{3}$ Mushtaq Laway ${ }^{3}$ \\ Nisar A. Chowdri ${ }^{2}$ Fazl Q. Parray ${ }^{2}$ \\ ${ }^{1}$ Department of General Surgery, Govt Medical College Hospital, \\ Address for correspondence Mudassir Ahmad Khan, MBBS, MS, \\ Rajouri, J\&K, India \\ 2 Department of Colorectal Surgery SKIMS, Srinagar, J\&K, India \\ ${ }^{3}$ Directorate of Health Services, J\&K, India \\ FACRSI, FCRS, Department of General Surgery, Govt Medical college \\ Hospital, Rajouri, J\&K, India (e-mail: khanmudassir925@gmail.com). \\ J Coloproctol 2021;41(2):131-137.
}

\begin{abstract}
Keywords

- low anterior resection

- covering ileostomy

- anastomotic stricture

- anastomotic leak

- rectal cancer
\end{abstract}

Background Colorectal resection anastomosis is the commonest cause of rectal strictures. Anastomotic site ischemia, incomplete doughnuts from stapled anastomosis and pelvic infection, are some of the risk factors that play a role in the development of postoperative rectal strictures. However, the role of diverting stoma in the development of rectal strictures has not been studied extensively.

Objectives To study the difference in the occurrence of anastomotic strictures (AS) in patients submitted to low anterior resection (LAR) with covering ileostomy $(\mathrm{Cl})$, and to LAR without $\mathrm{Cl}$ for carcinoma rectum.

Methods This was a prospective, comparative case control study carried out at a tertiary care referral center. Low anterior resection with covering ileostomy was performed in patients with rectum carcinoma in the study group, while LAR without covering ileostomy was performed in the control group. The study group had 29 patients, while the control group had 33 patients with rectum carcinoma.

Results During the mean follow-up period of 9.1 months, 8 (28\%) patients in the study group and $2(6 \%)$ patients in the control group developed AS $(p=0.019)$. Out of these 8 patients with AS in the study group, $50 \%$ had Grade-I AS, $25 \%$ had Grade-II AS, while $25 \%$ of the patients had Grade-III (severe) AS. However, both patients who developed AS in the control group had a mild type (Grade I) of AS.

Conclusion Covering ileostomy increases the chances of AS formation after LAR for rectum carcinoma. Also, the SKIMS Clinical Grading of Rectal Strictures is a simple and received

October 13, 2020

accepted

January 18, 2021
DOI https://doi.org/

$10.1055 / \mathrm{s}-0041-1730040$. ISSN 2237-9363. (c) 2021. Sociedade Brasileira de Coloproctologia. All rights reserved.

This is an open access article published by Thieme under the terms of the Creative Commons Attribution-NonDerivative-NonCommercial-License, permitting copying and reproduction so long as the original work is given appropriate credit. Contents may not be used for commercial purposes, or adapted, remixed, transformed or built upon. (https://creativecommons.org/ licenses/by-nc-nd/4.0/)

Thieme Revinter Publicações Ltda., Rua do Matoso 170, Rio de Janeiro, RJ, CEP 20270-135, Brazil 


\section{Resumo}

\author{
Palavras-chave \\ - ressecção anterior \\ baixa \\ - ileostomia de \\ proteção \\ - estenose \\ anastomótica \\ - vazamento \\ anastomótico \\ - câncer retal
}

handy tool available for every surgeon to grade, classify and monitor the postoperative rectal strictures.

Introdução A anastomose de ressecção colorretal é a causa mais comum de estenoses retais. A isquemia do local da anastomose, donuts (anéis) incompletos de anastomose grampeada e infecção pélvica são alguns dos fatores de risco que desempenham um papel no desenvolvimento de estenoses retais pós-operatórias. No entanto, o papel do estoma de desvio no desenvolvimento de estenoses retais não foi estudado extensivamente.

Objetivos Estudar a diferença na ocorrência de estenoses anastomóticas (EA) em pacientes submetidos à ressecção anterior baixa (LAR) com ileostomia de proteção e a LAR sem ileostomia de proteção para carcinoma de reto.

Métodos Este foi um estudo prospectivo e comparativo de caso-controle realizado em um centro de referência de atenção terciária. A ressecção anterior baixa com ileostomia de proteção foi realizada em pacientes com carcinoma de reto no grupo de estudo, enquanto LAR sem ileostomia de proteção foi realizada no grupo controle. $O$ grupo de estudo tinha 29 pacientes, enquanto o grupo controle tinha 33 pacientes com carcinoma de reto.

Resultados Durante o período de acompanhamento médio de 9, 1 meses, 8 (28\%) pacientes no grupo de estudo e 2 (6\%) pacientes no grupo controle desenvolveram EA $(p=0,019)$. Destes 8 pacientes com EA no grupo de estudo, $50 \%$ tinham EA de Grau I, $25 \%$ tinham EA de Grau II, enquanto 25\% dos pacientes tinham EA de Grau III (grave). No entanto, ambos os pacientes que desenvolveram EA no grupo de controle tinham um tipo leve (Grau I) de EA.

Conclusão A ileostomia de proteção aumenta as chances de formação de AS após LAR para carcinoma de reto. Além disso, o SKIMS Clinical Grading of Rectal Strictures é uma ferramenta simples e útil disponível para cada cirurgião para graduar, classificar e monitorar as estenoses retais pós-operatórias.

\section{Introduction}

Colorectal cancer is a disease with a major worldwide burden in terms of patient suffering and cost of treatment. Worldwide, colorectal cancer is the $2^{\text {nd }}$ most common cancer among women, and the $3^{\text {rd }}$ most common among men. ${ }^{1}$ Sphincter-preserving low anterior resection (LAR) with total mesorectal excision (TME) is now considered the standard operation for rectal cancer that allows a primary anastomosis to be created at a lower level. ${ }^{2}$ Anastomotic leakage (AL) rates ranging from $3 \%$ to $>20 \%$ have been reported, leading to substantial postoperative morbidity and mortality. ${ }^{3,4}$ Some authors have recommended the routine use of a temporary stoma to reduce the morbidity from $\mathrm{AL}^{5,6}$ In contrast, others have discouraged the routine use of temporary stomas, preferring selective use. For these authors, a protective stoma is only able to reduce the disastrous clinical consequences of $\mathrm{AL}$ and, instead of what is claimed by other authors, increases the burden with stoma-related complications. ${ }^{7,8}$ The overall incidence of clinical leak in colorectal anastomosis is $8 \%$; therefore, covering stoma confectioning in the majority of patients (92\%), if analyzed retrospectively, has minimal or no clinical usefulness. ${ }^{9}$
Moreover, the complications that can be caused by the stoma itself should not be ignored, as they include patient discomfort and inconvenience, high output with consequent dehydration and electrolyte imbalance, and anastomotic complications at the stoma closure site. ${ }^{10-16}$ Some studies have even reported that reversal of the stoma is associated with complications in up to $40 \%$ of the patients. ${ }^{17} \mathrm{~A}$ recent propensity-matched scoring analysis by Shiomi et al. including about one thousand patients who underwent one thousand who underwent LAR confirmed that defunctioning ileostomy does not influence the rate of clinical AL, but does mitigate the consequences of leakage, reducing the need for urgent reoperation. ${ }^{18}$

Rectal stricture is a chronic pathological narrowing involving a segment of the gut lumen that leads to difficulty in the passage of gut contents, resulting in clinical signs and symptoms of complete or partial bowel obstruction. ${ }^{19}$ However, prospective studies have defined a stricture anatomically in terms of the inability to pass a proctoscope ( $12 \mathrm{~mm}$ diameter) or a larger rigid sigmoidoscope $(19 \mathrm{~mm}$ diameter) through the $\mathrm{AS}^{20,21}$ The Cardiff classification ${ }^{22}$ graded strictures on a scale of 0 to 2 ; $(0=$ no stricture 
present; $1=$ reversible stricture with limited clinical impact; and 2 =irreversible stricture with severe clinical impact). Moreover, according to the Cardiff classification, anorectal stricture was defined as $\mathrm{S} 1$, for stenosis with presumed or associated mucosal inflammation, and S2, by the fibrotic appearance of the stricture. ${ }^{22}$

Rectal strictures may occur de novo after any pathological condition that causes rectal wall scarring or after colorectal resection anastomosis (the commonest type). Pathologically, rectal strictures may be benign or malignant. Clinically, rectal strictures may be asymptomatic or may present as bolus obstruction, constipation, diarrhea, urgency, or large bowel obstruction. ${ }^{19}$ Chronic rectal strictures may give rise to various complications, such as pelvic and perianal suppurations and fistula formation, stercoral or distention ulcer above the level of the stricture, chronic blood loss, malignant transformation, and chronic or acute intestinal obstruction. Anastomotic site ischemia, incomplete doughnuts from stapled anastomosis, and pelvic infection are some of the risk factors that play a role in the development of postoperative rectal strictures. However, the role of diverting stoma in the development of rectal strictures has not been studied extensively.

\section{Objectives}

To study and describe the difference in occurrence of ASs in patients submitted to LAR with covering ileostomy and to LAR without covering ileostomy for rectum carcinoma.

\section{Material and Methods}

The present prospective comparative case-control study was carried out from November 2016 to August 2018 in the Division of Colorectal Surgery at a tertiary care hospital in Kashmir, India. In the present study, rectum carcinoma patients were divided into two groups: LAR with covering ileostomy (LAR with $\mathrm{CI}$ ) in one group (study group), and LAR without covering ileostomy (LAR without $\mathrm{CI}$ ) in the other group (control group). The patients were fully evaluated before surgery and were assigned to the study or control group at the discretion of the operating surgeon. All patients were evaluated with detailed history and physical examination, and the diagnosis and the stage of disease were confirmed by Carcino-Embroyonic Antigen (CEA) levels, contrast enhanced computerized tomography (CECT) of the abdomen/chest/pelvis and, magnetic resonance imaging (MRI) of the pelvis. The parameters noted in all patients of both groups were age, gender, body mass index (BMI), occupation, dietary habit, smoking history, associated comorbidities, American Society of Anesthesiologists (ASA) score, location of the tumor in relation to the anal verge, Tumor-Node-Metastasis (TNM) stage, execution of neoadjuvant chemoradiotherapy, level of the anastomosis in relation to the anal verge, follow-up period, and postoperative digital rectal examination (DRE) findings.
Patients with stage I to IIIC rectal cancer according to the American Joint Committee on Cancers (AJCC) staging for rectal cancer were included in the present study. ${ }^{23}$ Rectum carcinoma patients of all age groups and both genders operated in elective settings and whose postoperative anastomotic line was within the reach of DRE were included. However, patients operated in emergency settings presenting with acute bowel obstruction, perforation and peritonitis, taking immunosuppressant drugs, with stage IV disease, and severe hypo-albuminemia (serum albumin $<2.5 \mathrm{~g} / \mathrm{dl}$ ) were excluded from the study. Also, the patients requiring restorative colorectal resections for benign diseases and rectum carcinoma patients with underlying Familial Adenomatous Polyposis (FAP) requiring Total Proctocolectomy (TPC) with Ileal Pouch Anal Anastomosis (IPAA) were not included.

Since the definitions, classifications and grading systems of rectal strictures are ambiguous, and none of them is universally accepted, we used our own institutional clinical grading classification of rectal strictures based on DRE to describe the ASs; a readily available tool for every surgeon. We refer to this classification as the SKIMS Clinical Grading of Rectal Strictures'. SKIMS stands for Sheri-Kashmir Institute of Medical Sciences, the institute where the present study was undertaken. In the present study, we have discussed the postoperative anastomotic rectal strictures according to the SKIMS Clinical Grading of Rectal Strictures (-Table 1). Postoperatively, we followed the patients of both groups for a maximum period of 22 months and noted the development of AS. To observe the occurrence and the grade of ASs, DRE was performed at least twice in every patient by an experienced coloproctologist at 6 weeks and 12 weeks postopertaively. Thereafter, the DRE was repeated on a need basis. The DRE findings about AS were noted down according to the SKIMS Clinical Grading of Rectal Strictures'.

\section{Statistical Analysis}

The data was compiled and statistically analyzed using the chi-squared test, the t-test and the Fisher exact test, and

Table 1 SKIMS Clinical Grading of Rectal Strictures

\begin{tabular}{|l|l|l|}
\hline $\begin{array}{l}\text { Grade of } \\
\text { Stricture }\end{array}$ & Severity & Description \\
\hline I & Mild & $\begin{array}{l}\text { Allowing passage of the index finger } \\
\text { on DRE with mild or no resistance } \\
\text { and index finger hugging the rectal } \\
\text { stricture circumferentially without } \\
\text { causing pain. }\end{array}$ \\
\hline II & Moderate & $\begin{array}{l}\text { Allowing passage of the index finger } \\
\text { on DRE but with significant resis- } \\
\text { tance at the level of the stricture, } \\
\text { and patient feeling pain on DRE. }\end{array}$ \\
\hline III & Severe & $\begin{array}{l}\text { Strictures not allowing at all the } \\
\text { passage of the index finger on DRE, } \\
\text { even under pressure. }\end{array}$ \\
\hline
\end{tabular}

Abbreviation: DRE, digital rectal examination. 
inferences were drawn from the results of the statistical analysis. IBM SPSS Statistics for Windows, version 20.0 (IBM Corp., Armonk, NY, USA) was used for the statistical analysis of the compiled data.

\section{Results}

After excluding the patients who did not fulfill the inclusion criteria, the total number of patients included in the present study was 62. Among these, 29 patients were included in the study group (LAR with $\mathrm{CI}$ ), and 33 patients were included in the control group (LAR without CI). More than $95 \%$ of the patients in both groups underwent LAR for rectal cancer, and total of only 3 (4.5\%) patients underwent anterior resection. In the majority of the patients in both groups, circular staplers were used for anastomosis. It is also worth mentioning that most of the patients in both groups were operated by the open approach ( 83 versus $91 \% ; p=0.912$ ). The mean postoperative follow-up period was of $9.146 \pm 3.50$ months (maximum of 22 months).

The mean age of the patients in the study group was $49.31 \pm 15.85$ years old, while in the control group, the mean age was $57.91 \pm 14.73$ years old, and this difference in the mean age was statistically significant $(p=0.031)$. The study group had more patients in younger age groups, while the control group had more patients in elderly age groups. Out of 29 patients in the study group, 17 (58.6\%) had received neoadjuvant therapy, while $12(41.4 \%)$ out of 33 patients in the control group had received neoadjuvant therapy. However, this difference was not statistically significant $(p=0.080)$.

The Colon Leakage Score $(p=0.154)$, the mean distance of the tumor from the anal verge $(p=0.087)$ and the level of anastomosis after surgery $(p=0.148)$ in both groups were statistically insignificant (-Table 2). Similarly, there were no statistically significant differences between the study and control groups regarding gender distribution $(p=0.191)$, mean BMI $(p=0.317)$, preoperative hemoglobin $(p=0.281)$, serum albumin levels $(p=0.274)$, comorbidity status $(p=0.316)$, smoking history $(p=0.624)$, ASA grade $(p=0.306)$, and tumor grade and tumor stage $(p=0.665)$.

The anastomotic leak $(\mathrm{AL})$ rate (-Fig. 1 ) in the study group was of $14 \%$ ( 4 out of 29 ), and in the control group it was $18 \%$

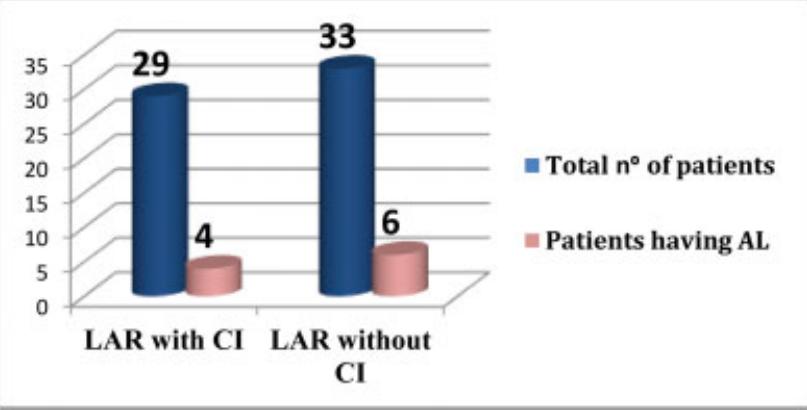

Fig. 1 Anastomotic leak.

(6 out of 33). Thus, the AL rate was higher significantly $(p=0.035)$ in the control group than in the study group. This difference in the AL rate between the two groups may be explained by the preventive effect of the covering ileostomy in decreasing the AL rate.

We observed that, during the mean follow-up period of 9.1 months, 8 (28\%) patients in the study group and $2(6 \%)$ patients in the control group developed AS. The p-value (0.019) was statistically significant regarding the development of AS in both groups (-Table 3, - Fig. 2). Out of the 8 patients with AS in the study group, strictures in 4 (50\%) patients were of the mild type (Grade I), which allowed the passage of the index finger easily on DRE. However, in $2(25 \%)$ patients, the strictures were moderate (Grade II) and allowed the passage of the index finger with significant resistance at the level of the stricture, while 2 (25\%) patients had severe strictures (Grade III) that did not allow the passage of the index finger on DRE. However, both patients (100\%) who developed strictures in the control group had a mild type (Grade I) of AS.

Grade I ASs were managed by a high fiber diet and stool bulking agents. Grade II strictures were managed by regular digital rectal dilatations by the patient himself or by the attendant (after proper teaching). Severe (Grade III) strictures were put on the clinical dilatation protocol in the hospital setting by the operating surgeon using Hager metallic dilators. However, the outcome of this overall treatment protocol for these ASs was not studied in the present study.

Table 2 Parameters Affecting Anastomotic Leakage

\begin{tabular}{|l|l|l|l|l|}
\hline Patient Group & $\begin{array}{l}\text { Statistical } \\
\text { parameter }\end{array}$ & $\begin{array}{l}\text { Colon Leakage } \\
\text { Score }\end{array}$ & $\begin{array}{l}\text { Distance of } \\
\text { tumor from } \\
\text { the AV }(\mathrm{cm})\end{array}$ & $\begin{array}{l}\text { Level of } \\
\text { anastomosis } \\
(\mathrm{cm} \text { from the AV) }\end{array}$ \\
\hline \multirow{2}{*}{ LAR with CI $(n=29)$} & Mean & 10.65 & 5.34 & 4.00 \\
\cline { 2 - 5 } & SD & 3.716 & 2.486 & 1.890 \\
\hline \multirow{2}{*}{ LAR without CI $(n=33)$} & Mean & 9.58 & 7.50 & 5.15 \\
\cline { 2 - 5 } & SD & 4.50 & 2.398 & 2.093 \\
\hline p-value & & 0.154 & 0.087 & 0.148 \\
\hline
\end{tabular}

Abbreviations: AV, anal verge; $\mathrm{Cl}$, covering ileostomy; LAR, low anterior resection; SD, standard deviation. 
Table 3 Anastomotic Stricture

\begin{tabular}{|l|l|l|l|l|l|l|}
\hline \multirow{2}{*}{ GROUP } & \multirow{2}{*}{$\begin{array}{l}\text { Total number of } \\
\text { patients }\end{array}$} & \multicolumn{4}{l|}{ Patients developing anastomotic stricture } & $\begin{array}{l}\text { Total percentage of patients } \\
\text { Developing stricture }\end{array}$ \\
\cline { 3 - 7 } & & Grade I & Grade II & Grade III & Total & \\
\hline LAR with CI & 29 & 4 & 2 & 2 & 8 & $28 \%$ \\
\hline LAR without CI & 33 & 2 & 0 & 0 & 2 & $6 \%$ \\
\hline p-value & & & & 0.019 \\
\hline
\end{tabular}

Abbreviations: $\mathrm{Cl}$, covering ileostomy; LAR, low anterior resection.

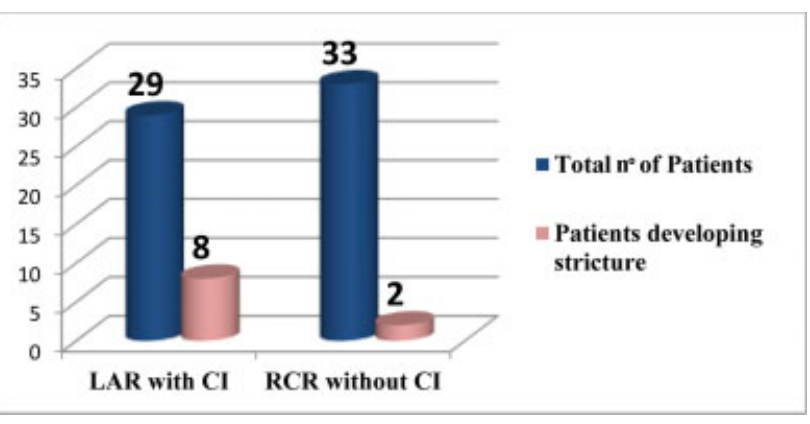

Fig. 2 Anastomotic stricture.

\section{Discussion}

Development of AL or of AS is the result of faulty healing at the anastomotic line. And there is a multitude of diseases and patient-related, surgeon-related and surgical technique-related factors that influence healing at the site of anastomosis. Most colorectal surgeons would agree that adherence to good surgical principles is the best determinant for optimum healing of colorectal anastomoses. In recent years, randomized control studies that directly compared anastomotic techniques have been largely abandoned, given the perception that the technique itself (hand sewing, circular versus linear stapler, one layer versus two layers) is not a sole factor responsible for $\mathrm{AL}$, assuming that good surgical principles are followed. The one exception to this generalization has been the stricture rate with staplers. Circular staplers are reported to have higher stricture rates when compared with linear stapling. $^{24,25}$ However, even well-perfused, well-constructed anastomoses without any tension along the anastomotic line can develop an AL or AS. Despite the belief of surgeons in their own surgical techniques and predictive capabilities, clinical studies demonstrate that surgeons cannot predict with absolute accuracy which anastomoses will develop leak or stricture and which will not. ${ }^{26}$ The several proposed reasons for the development of AS include ischemia, tension along the anastomotic line, subacute obstruction, circular staplers, narrow diameter staplers, and the occurrence of an AL. ${ }^{27}$ The pathophysiology for the development of AS is assumed to be a local inflammation that results in collagen overproduction and in poor bowel wall remodeling. ${ }^{28}$ The incidence of colorectal AS varies from 3 to $30 \%$, ${ }^{29}$ and is considered to be related to various patient- and treatment-related factors, including radiation ${ }^{30}$ and $\mathrm{AL}^{31}$ Most of these anastomotic strictures are simple fibrous constrictions that can be successfully treated by regular stricture dilation using different techniques. However, up to $28 \%$ of the patients require a surgical correction. This can be technically difficult, and a permanent colostomy may be needed. ${ }^{32}$ In a nutshell, studies reveal that while meticulous attention to the tenets of good surgical practice are important and should be rigorously adhered to, there still are some factors that significantly impact anastomotic healing that are not yet fully understood. ${ }^{28}$ One of these understudied factors is the role of diverting stoma in the development of AS, and in the present study, we tried to elucidate the role of $\mathrm{CI}$ in the causation of ASs.

Since the Colon Leakage Score (CLS) in both groups was comparable and determines the risk of $\mathrm{AL}$ in left-sided restorative colorectal resection. Therefore, the two groups in our study were theoretically identical regarding the risk of AL. But, practically, the AL rates (-Fig. 1) in the study and control groups were of $\sim 14 \%$ and $18 \%$, respectively. Thus, the AL rate was significantly higher $(p=0.035)$ in the control group than in the study group. This difference in the AL rate between the two groups may be explained by the preventive effect of the $\mathrm{CI}$ in decreasing the $\mathrm{AL}$, as the CLS does not take into account the role of $\mathrm{CI}$ in decreasing the AL.

The total incidence of AS in the study group was of $28 \%$, while in the control group it was only of $6 \%$. The higher incidence of AS formation in the study group may be explained by the absence of the regular dilating effect of solid formed stools passing via the anastomotic site. Kumar et al., ${ }^{33}$ in a retrospective analysis of data from 108 patients with rectal carcinoma who underwent AR or LAR, reported that $19(17.6 \%)$ patients developed ASa at a median duration of 8 months (range: 3-20 months). Werre et al. also reported that $8.2 \%$ (21 out of 256) patients who underwent LAR developed anastomotic site stricture. ${ }^{34}$ Paluvoi et al. ${ }^{35}$ also mentioned that patients may have developed AS after low rectal anastomosis with diverting ileostomy, and suggested that rectal anastomosis should be endoscopically examined prior to reversing the protective stoma and emphasized the role of transillumination flexible endoscopy in case the lumen is not properly visualized.

Anastomotic healing complications of postoperative leak and stricture continue to plague surgeons despite many broadly targeted interventions. The efficacy evaluation of preventive measures is difficult due to inconsistent 
definitions and reporting of these complications. Few interventions have been shown to impact rates of leakage or stricture. However, new evidence that the intestinal microbiota can play an important role in the development of anastomotic complications is emerging. The development of an AS is a result of the complex interactions between genetics, the gut microbiome, operative technique, antecedent health and comorbidities of the patient, prior patient exposures, and the subsequent hospital course and exposures ranging from infectious agents to antibiotics. ${ }^{27}$ A more holistic approach to understanding the mechanisms of anastomotic complications is needed in order to develop tailored interventions to reduce their frequency. Such an approach may require a more complete definition of the role of the microbiota in anastomotic healing.

Although one of the prominent identified risk factors for stricture is AL, there are situations in which ASs form outside of the setting of anastomotic site ischemia, of the anastomotic tension, and of the AL. These situations and risk factors are unknown. ${ }^{36}$ In our study, we also observed that the AL was significantly higher in the control group but, paradoxically, this group of patients had a significantly lower stricture rate than the study group. This paradox explains that the AL is not the sole factor responsible for the development of AS, and this observation suggests that there is a strong possibility of diversion $\mathrm{CI}$ having some role in the formation of ASs. And the plausible explanation for the increased frequency of AS after LAR with $\mathrm{CI}$ seems to be the lack of movement of solid formed stools across the anastomotic line. This divests the anastomotic line from the regular dilating effect of solid formed stools during the early phase of anastomotic healing. Another factor that may have a role in the causation of AS after LAR with $\mathrm{CI}$ is that diverting ileostomy also deprives the anastomotic site from the normal gut microbiome, which, in turn, may lead to the alteration of normal anastomotic healing, resulting in stricture formation.

Finally, most endoscopic studies in which the anastomosis can be reached and dilated have not attempted to classify strictures in a defined way that might advance our understanding of their pathogenesis and their response to treatment. Therefore, in order to simplify the grading system of the ASs for the surgeon, we introduced our SKIMS Clinical Grading of Rectal Strictures. This allows the surgeon to classify the stricture on an Out Patient Department (OPD) basis by simple DRE, without any need of bowel preparation and sedation, as is required for endoscopic examinations.

\section{Conclusion}

The rate of postoperative AS formation is of $28 \%$ in patients of the study group, while in the control group, only $6 \%$ of the patients developed AS. This finding suggests that $\mathrm{CI}$ increases the chances of AS formation after LAR for rectum carcinoma. Also, the SKIMS Clinical Grading of Rectal Strictures is a simple and handy tool available for every surgeon to grade, classify, and monitor the postoperative rectal strictures.

\section{Limitations of the Present Study}

Since the present study is a small sized, nonrandomized study, we suggest that further large sized, multi-institutional randomized controlled trials (RCTs) be performed in order to confirm or refute our results.

\section{Author Contributions}

All authors have contributed equally to the present study.

\section{Funding Information}

The present research project did not receive any grants from any funding agency in the public, commercial, or not-for-profit sectors.

\section{Conflict of Interests}

The authors have no conflict of interests to declare.

\section{Acknowledgements}

We acknowledge the support of all our staff at the Colorectal Surgery Division in the department of General surgery at the SKIMS, Srinagar Kashmir.

\section{References}

1 Ferlay J, Shin HR, Bray F, Forman D, Mathers C, Parkin DM. Estimates of worldwide burden of cancer in 2008: GLOBOCAN 2008. Int J Cancer 2010;127(12):2893-2917

2 Griffen FD, Knight CD Sr, Whitaker JM, Knight CD Jr. The double stapling technique for low anterior resection. Results, modifications, and observations. Ann Surg 1990;211(06):745-751, discussion 751-752

3 Bertelsen CA, Andreasen AH, Jørgensen T, Harling HDanish Colorectal Cancer Group. Anastomotic leakage after curative anterior resection for rectal cancer: short and long-term outcome. Colorectal Dis 2010;12(7 Online):e76-e81

4 Eberl T, Jagoditsch M, Klingler A, Tschmelitsch J. Risk factors for anastomotic leakage after resection for rectal cancer. Am J Surg 2008;196(04):592-598

5 Chude GG, Rayate NV, Patris V, et al. Defunctioning loop ileostomy with low anterior resection for distal rectal cancer: should we make an ileostomy as a routine procedure? A prospective randomized study. Hepatogastroenterology 2008;55(86-87):1562-1567

6 Pata G, D'Hoore A, Fieuws S, Penninckx F. Mortality risk analysis following routine vs selective defunctioning stoma formation after total mesorectal excision for rectal cancer. Colorectal Dis 2009;11(08):797-805

7 Karanjia ND, Corder AP, Bearn P, Heald RJ. Leakage from stapled low anastomosis after total mesorectal excision for carcinoma of the rectum. Br J Surg 1994;81(08):1224-1226

8 Karanjia ND, Corder AP, Holdsworth PJ, Heald RJ. Risk of peritonitis and fatal septicaemia and the need to defunction the low anastomosis. Br J Surg 1991;78(02):196-198

9 Hautefeuille P, Valeur P, Perniceni T, et al. Functional and oncologic results after colo-anal anastomosis for low rectal carcinoma. Ann Surg 1988;207(01):61-64

10 Bakx R, Busch OR, Bemelman WA, Veldink GJ, Slors JF, van Lanschot JJ. Morbidity of temporary loop ileostomies. Dig Surg 2004;21(04):277-281

11 Cipe G, Erkek B, Kuzu A, Gecim E. Morbidity and mortality after the closure of a protective loop ileostomy: analysis of possible predictors. Hepatogastroenterology 2012;59(119):2168-2172

12 Hallböök O, Matthiessen P, Leinsköld T, Nyström PO, Sjödahl R. Safety of the temporary loop ileostomy. Colorectal Dis 2002;4 (05):361-364 
13 Kaiser AM, Israelit S, Klaristenfeld D, et al. Morbidity of ostomy takedown. J Gastrointest Surg 2008;12(03):437-441

14 Laurent C, Nobili S, Rullier A, Vendrely V, Saric J, Rullier E. Efforts to improve local control in rectal cancer compromise survival by the potential morbidity of optimal mesorectal excision. J Am Coll Surg 2006;203(05):684-691

15 Law WL, Chu KW, Choi HK. Randomized clinical trial comparing loop ileostomy and loop transverse colostomy for faecal diversion following total mesorectal excision. Br J Surg 2002;89(06): 704-708

16 van Westreenen HL, Visser A, Tanis PJ, Bemelman WA. Morbidity related to defunctioning ileostomy closure after ileal pouch-anal anastomosis and low colonic anastomosis. Int J Colorectal Dis 2012;27(01):49-54. doi: 10.1007/s00384-011-1276-7. PMID: 21761119

17 Åkesson O, Syk I, Lindmark G, Buchwald P. Morbidity related to defunctioning loop ileostomy in low anterior resection. Int J Colorectal Dis 2012;27(12):1619-1623

18 Shiomi A, Ito M, Maeda K, et al. Effects of a diverting stoma on symptomatic anastomotic leakage after low anterior resection for rectal cancer: a propensity score matching analysis of 1,014 consecutive patients. J Am Coll Surg 2015;220(02):186-194

19 Garcea G, Sutton CD, Lloyd TD, Jameson J, Scott A, Kelly MJ. Management of benign rectal strictures: a review of present therapeutic procedures. Dis Colon Rectum 2003;46(11):1451-1460. Doi: 10.1007/s10350-004-6792-x

20 Brochard C, Siproudhis L, Wallenhorst T, et al. Anorectal stricture in 102 patients with Crohn's disease: natural history in the era of biologics. Aliment Pharmacol Ther 2014;40(07):796-803

21 Bannura GC, Cumsille MA, Barrera AE, Contreras JP, Melo CL, Soto DC. Predictive factors of stenosis after stapled colorectal anastomosis: prospective analysis of 179 consecutive patients. World J Surg 2004;28(09):921-925

22 Hughes LE. Clinical classification of perianal Crohn's disease. Dis Colon Rectum 1992;35(10):928-932. Doi: 10.1007/BF02253493 [PMID: 1395978]

23 Edge SB, Compton CC. The American Joint Committee on Cancer: the 7th edition of the AJCC cancer staging manual and the future of TNM. Ann Surg Oncol 2010;17(06):1471-1474

24 Castro PM, Ribeiro FP, Rocha Ade F, Mazzurana M, Alvarez GA. Hand-sewn versus stapler esophagogastric anastomosis after esophageal ressection: systematic review and meta-analysis. Arq Bras Cir Dig 2014;27(03):216-221
25 Wang W-P, Gao Q, Wang K-N, Shi H, Chen L-Q. A prospective randomized controlled trial of semi-mechanical versus handsewn or circular stapled esophagogastrostomy for prevention of anastomotic stricture. World J Surg 2013;37(05):1043-1050

26 Karliczek A, Harlaar NJ, Zeebregts CJ, Wiggers T, Baas PC, van Dam GM. Surgeons lack predictive accuracy for anastomotic leakage in gastrointestinal surgery. Int J Colorectal Dis 2009;24(05):569-576

27 Hashemi M, Novell JR, Lewis AA. Side-to-side stapled anastomosis may delay recurrence in Crohn's disease. Dis Colon Rectum 1998; 41(10):1293-1296

28 Guyton KL, Hyman NH, Alverdy JC. Prevention of Perioperative Anastomotic Healing Complications: Anastomotic Stricture and Anastomotic Leak. Adv Surg 2016;50(01):129-141. Doi: 10.1016/ j.yasu.2016.03.011

29 Chen TA, Hsu WL. Successful treatment of colorectal anastomotic stricture by using sphincterotomes. Front Surg 2014;1:22(1-3). Doi: 10.3389/fsurg.2014.00022. PMID: 25593946

30 Anseline PF, Lavery IC, Fazio VW, Jagelman DG, Weakley FL. Radiation injury of the rectum: evaluation of surgical treatment. Ann Surg 1981;194(06):716-724. Doi: 10.1097/00000658198112000-00010

31 Lim M, Akhtar S, Sasapu K, et al. Clinical and subclinical leaks after low colorectal anastomosis: a clinical and radiologic study. Dis Colon Rectum 2006;49(10):1611-1619. Doi: 10.1007/s10350006-0663-6

32 Schlegel RD, Dehni N, Parc R, Caplin S, Tiret E. Results of reoperations in colorectal anastomotic strictures. Dis Colon Rectum 2001;44(10):1464-1468. Doi: 10.1007/BF02234598

33 Kumar A, Daga R, Vijayaragavan P, et al. Anterior resection for rectal carcinoma - risk factors for anastomotic leaks and strictures. World J Gastroenterol 2011;17(11):1475-1479

34 Werre A, Mulder C, van Heteren C, Bilgen ES. Dilation of benign strictures following low anterior resection using Savary-Gilliard bougies. Endoscopy 2000;32(05):385-388. Doi: 10.1055/s-20008999 [PMID: 10817177]

35 Paluvoi NV, Lee SW. Patient Develops Anastomotic Stricture After Low Anastomosis with Diverting Ileostomy. In: Lee S, Steele S, Feingold D, Ross H, Rivadeneira D, eds. Colorectal Surgery Consultation. Cham: Springer; 2019. Doi: 10.1007/978-3-03011181-6_30

36 Baird R, Laberge J-M, Lévesque D. Anastomotic stricture after esophageal atresia repair: a critical review of recent literature. Eur J Pediatr Surg 2013;23(03):204-213 